\title{
Disability and Related Factors among Road Traffic Accident Victims in Benin: Study from Five Public and Faith-Based Hospitals in Urban and Suburban Areas
}

\author{
Yolaine Glèlè-Ahanhanzo', Alphonse Kpozèhouen ${ }^{1}$, Noël Moussiliou Paraïso², \\ Patrick Makoutodé ${ }^{3}$ Chabi O. Alphonse Biaou' ${ }^{1}$, Eric Remacle ${ }^{4}$, \\ Edgard-Marius Ouendo ${ }^{3}$, Alain Levêque ${ }^{5}$ \\ ${ }^{1}$ Epidemiology and Biostatistics Department, Public Health Regional Institute, Ouidah, Benin \\ ${ }^{2}$ Health Promotion Department, Public Health Regional Institute, Ouidah, Benin \\ ${ }^{3}$ Policies and Health Systems Department, Public Health Regional Institute, Ouidah, Benin \\ ${ }^{4}$ Humanité Inclusion, Brussels, Belgium \\ ${ }^{5}$ Center of Research in Epidemiology, Biostatistics and Clinical Research, School of Public Health, Université Libre de Bruxelles, \\ Brussels, Belgium \\ Email: nyglele@yahoo.fr
}

How to cite this paper: Glèlè-Ahanhanzo, Y., Kpozèhouen, A., Paraïso, N.M., Makoutodé, P., Biaou, C.O.A., Remacle, E., Ouendo, E.-M. and Levêque, A. (2018) Disability and Related Factors among Road Traffic Accident Victims in Benin: Study from Five Public and Faith-Based Hospitals in Urban and Suburban Areas. Open Journal of Epidemiology, 8, 226-241. https://doi.org/10.4236/ojepi.2018.84018

Received: October 30, 2018

Accepted: November 25, 2018

Published: November 28, 2018

Copyright ( 92018 by authors and Scientific Research Publishing Inc. This work is licensed under the Creative Commons Attribution International License (CC BY 4.0).

http://creativecommons.org/licenses/by/4.0/ (c) (i) Open Access

\begin{abstract}
Introduction: Road traffic accidents (RTAs) are a major public health issue in developing countries, where roads tend to be built haphazardly and accidents take a heavy toll on victims-including leaving them disabled. This study seeks to identify those factors that cause RTA victims to become disabled as a result of their injuries. Methods: This retrospective community-based study looked at RTA victims treated in five public and faith-based hospitals in Benin. Disability was evaluated using the Washington Group on Disabilities Statistics questionnaire. The independent variables were related to the victim's socio-demographic traits, the circumstances of the accident, and post-crash response mechanisms. The proportions were compared using the chi-squared test, with a threshold of $5 \%$. Results: The prevalence of disability among road traffic accident victims is $9.59 \%$ (CI 95\%: 6.86\% - 13.20\%). The occurrence of disability is associated with age $(p=0.002)$, occupational group $(p=0.0077)$, the mode of transport used to transfer the victim $(p<0.001)$ and the location of the injuries $(p=0.0035)$. The study also found that people fail to make sufficient use of post-crash response mechanisms. Conclusion: Public policy-makers should therefore focus on stepping up interventions to get more people using both protective equipment and post-crash response services.
\end{abstract}




\section{Keywords}

Traffic Accident, Disabled Persons, Risk Factors

\section{Introduction}

Road traffic accidents (RTAs) are a major public health issue because of their scale and the extent of their impact, especially in developing countries. According to the World Health Organization (WHO), RTAs account for 1.25 million deaths each year and as many as 50 million people suffer injuries as a result of RTAs [1]. This latent epidemic has a significant socio-economic cost to countries for two reasons. First, RTAs affect young working-age people (15 - 44 years) more than other groups. And second, the costs of dealing with the fallout of RTAs - to individuals and society as a whole - can be as high as $3 \%$ of gross domestic product (GDP) [2] [3]. Despite existing interventions [4] and progress on reducing morbidity and mortality rates, RTAs remain a major public health issue, even in developed countries [5] [6]. Low-income and middle-income countries continue to pay the heaviest price, accounting for more than $90 \%$ of all RTA-related deaths and injuries. Moreover, Africa is the most affected region of the world, where the most vulnerable road users (pedestrians, cyclists and motorcyclists) make up $60 \%$ of victims. RTA-related injury incidence is especially high in Africa, at an estimated 92.2 per 100,000 population [7]. The main consequences of these injuries are impairments that cause incapacity and, potentially, disability. According to the WHO, "Disability is not just a health problem. It is a complex phenomenon, reflecting the interaction between features of a person's body and features of the society in which he or she lives". An estimated $15 \%$ of the world's population lives with a disability [8]. Because disabled people face social interaction challenges, specific interventions are required to enable them to access certain services and address particular needs. RTA victims whose injuries leave them disabled join a group with specific needs. That is why, for planning purposes, it is important to estimate how prevalent the phenomenon is and what factors lie behind it. Post-RTA disability statistics are hard to come by because of the complexity of monitoring victims and the sheer diversity of incapacity and disability definitions and classifications. A 2004 literature review found that the prevalence of disability among RTA victims varied wildly from one study to the next-from as little as $2 \%$ to as high as $87 \%$. However, the authors stressed that very little data was available on the situation in developing countries, precisely where this new epidemic is at its highest. Although parsimonious, the literature mentions the following risk factors for post-RTA disability: age, educational level and socio-economic level [9].

According to WHO extrapolated estimates, there were 2855 RTA-related deaths in Benin in 2015, with a mortality rate of 27.7 per 100,000 population. Official statistics from Benin's National Road Safety Centre (CNSR) show that, 
in 2016, police recorded 5939 accidents with 629 fatalities and 4851 injuries. Of these accidents, $80 \%$ were in urban areas and around $50 \%$ of the vehicles involved were powered two-wheelers [10]. The scarce hospital data that is available mainly concerns clinical aspects of RTA victims' treatment and gives no indication of the situation as regards post-RTA disability. This study seeks to support planning around post-RTA disability management interventions by estimating the prevalence of post-RTA disability and identifying the associated factors.

\section{Methods}

\subsection{Context}

The study was conducted in the cities of Cotonou and Calavi in southern Benin-the country's two biggest urban and suburban conurbations accounting for $12 \%$ of its total population. According to projections from the most recent census, the cities had a combined population of 1,498,506 in 2017, living in an area spanning $729 \mathrm{~km}^{2}$ [11] [12]. In terms of health infrastructure, the cities are covered by five health districts and have five public or publicly affiliated faith-based hospitals: Abomey-Calavi Hospital, the National Teaching Hospital (CNHU), Saint Luc Hospital, Ménontin Hospital, and Suru-Léré Hospital.

\subsection{Type of Study, Population and Sampling}

This retrospective, cross-sectional, descriptive, analytical study was carried out in July 2018. The population comprised RTA victims treated in the five public and faith-based hospitals in Cotonou and Calavi. The survey population included people who were aged 18 years or over, were admitted to hospital between 1 April 2017 and 31 March 2018, had a contact number in their medical record or in the hospital register, and were alive the last time contact was made. Based on these criteria, a population of 3771 subjects was obtained. The targets were then selected through a process of systematic random sampling. The sample size was calculated using the Schwartz formula, with an expected post-RTA disability prevalence rate of $50 \%$ (given that we did not have suitable prevalence data regarding the phenomenon) and accuracy of $5 \%$.

$$
n=\frac{z_{\alpha} \times p \times(1-p)}{i^{2}}
$$

- $Z$ score (standard normal distribution of error risk) $\alpha=5 \%: Z_{\alpha}=1.96$.

- Prevalence of post-RTA disability: $p=50 \%$, or 0.5 .

- Accuracy. $i=5 \%$, or 0.05 .

- $n=384$.

Given that the reliability of the information contained in the hospital records (especially telephone numbers) was unknown, 943 subjects were selected via systematic random sampling with a sampling interval of 4, and 904 of these subjects were contacted. The sample excluded subjects who could not be contacted by telephone (line dead or subject not reachable at the given number), subjects who did not consent to participate, and subjects who were not present in Coto- 
nou or Calavi at the time of the survey.

\subsection{Techniques, Data Collection Tools and Variables}

The data were collected via structured interviews using a pre-tested questionnaire. The questionnaire administered by the researcher covered the following aspects: the victim's socio-demographic traits, the circumstances of the accident, a description of the immediate post-crash interventions, primary care seeking, and a description of the victim's disability.

Disability, as the dependent variable, was evaluated using the six-question Washington Group on Disability Statistics questionnaire [13] [14] covering six areas of impairment:

$\checkmark$ Vision: Do you have difficulty seeing, even if wearing glasses?

$\checkmark$ Hearing: Do you have difficulty hearing, even if using a hearing aid?

$\checkmark$ Mobility: Do you have difficulty walking or climbing steps?

$\checkmark$ Memory: Do you have difficulty remembering or concentrating?

$\checkmark$ Self-care: Do you have difficulty (with self-care such as) washing all over or dressing?

$\checkmark$ Communication: Using your usual (customary) language, do you have difficulty communicating, for example understanding or being understood?

Respondents gave an answer on a scale of 1 to 4 , depending on how difficult they found the task(s) described in each question.

$\checkmark \quad 1=$ No-no difficulty.

$\checkmark 2=$ Yes-some difficulty.

$\checkmark 3=$ Yes-a lot of difficulty.

$\checkmark 4$ = Cannot do at all.

People are considered "disabled" - and therefore at greatest risk of experiencing social participation restrictions-if they answer "Yes-a lot of difficulty" or "Cannot do at all".

The independent variables concerned potential explanatory factors for the disability, namely: the victim's socio-demographic traits (age, gender, education, occupational group, marital status, socio-economic well-being), the circumstances of the accident (environmental characteristics, characteristics of the conflict, user type, use of protective equipment, types of vehicle involved in the accident), the description of the immediate post-crash interventions (emergency services response and response time, who was responsible for transporting the victim, what mode of transport was used to transport the victim), primary care seeking (type of entity providing primary care, time between the accident and administration of primary care, location of injuries, number of injuries).

To define socio-economic well-being we used the poverty index of the Demographic and Health Surveys. It is a composite index of the socio-economic status that assigns weightings or factor scores obtained by principal component analysis of information collected on household assets. Despite its limitations, it is admitted as an acceptable indicator of socio-economic well-being [15]. Here, each 
respondent is ranked according to the household asset score and is assigned to poverty tertiles as follows: the poorest (Poor), the average (Average), and the wealthiest (Rich).

\subsection{Data Processing and Analysis}

The data were processed using the EpiData 3.1 and Stata 11 software programs. Descriptive statistics are presented as a mean (standard deviation), or as a median (interquartile range) for quantitative variables. Qualitative data are presented as a percentage. We used univariate analysis (chi-squared test or Fisher's exact test) to compare the proportions, and the Kruskal-Wallis test to compare the medians. We also used multiple logistic regression. A difference was considered statistically significant for $p$ values of less than or equal to 0.05 . We assessed associations between the dependent variable ("disability") and the other variables using odds ratios (ORs) followed by the confidence interval of 95\% (CI $95 \%)$.

\subsection{Ethical Considerations}

The protocol was submitted to the Faculty of Health Sciences' Health Sciences Research Ethics Committee. When recruiting participants, the researchers informed the subjects of the purpose of the study, the fact that it was anonymous, and their right to agree or refuse to participate. They were also told that they could withdraw from the study if they wished to do so. All participants were asked to give clear, informed consent by signing a form to that effect after reading a detailed explanatory note. Only respondents who signed the form participated in the study. From an administrative perspective, written consent was obtained from entities involved in the study before the data collection process began.

\section{Results}

\subsection{Description of the Sample}

\subsubsection{Socio-Economic Traits of RTA Victims}

At the time of the survey, the average age of the RTA victims was $37.9 \pm 12.5$ years, with 6 out of 10 subjects aged between 25 and 44 years. The majority of the subjects were male (79.36\%). More than two-thirds of the subjects (67.67\%) were educated to secondary level or above and most were in work, with 6 out of 10 subjects having a self-employed occupation (freelance professional, shopkeeper/trader, crafts/tradesperson) (Table 1). At the time of the RTA, 7 out of 10 subjects were the head of the household and the same proportion were cohabiting with a partner. Around 6 out of 10 victims had at least 3 dependants when the RTA occurred.

\subsubsection{Circumstances of the RTA}

Most of the accidents occurred in Cotonou and Calavi (87.95\%), during the day 
Table 1. Socio-economic traits of the RTA victims $(n=365)$, July 2018.

\begin{tabular}{|c|c|c|c|}
\hline Variables & & Number & $\%$ \\
\hline \multirow[t]{4}{*}{ Current age (years) } & Under 25 & 45 & 12.33 \\
\hline & $25-44$ & 219 & 60.00 \\
\hline & $45-59$ & 73 & 24.38 \\
\hline & 60 and above & 28 & 3.29 \\
\hline Gender & Female & 79 & 21.64 \\
\hline \multirow[t]{5}{*}{ Level of education } & No education & 39 & 10.68 \\
\hline & Basic literacy & 5 & 1.37 \\
\hline & Primary school & 74 & 20.27 \\
\hline & Secondary school & 141 & 38.63 \\
\hline & Higher education & 106 & 29.04 \\
\hline \multirow[t]{8}{*}{ Occupation } & Pupil/student & 29 & 7.95 \\
\hline & Freelance professional & 113 & 30.96 \\
\hline & Civil servant & 69 & 18.90 \\
\hline & Shopkeeper/trader & 55 & 15.07 \\
\hline & Housekeeper & 2 & 0.55 \\
\hline & Crafts/tradesperson & 67 & 18.36 \\
\hline & Unemployed & 7 & 1.92 \\
\hline & Other & 23 & 6.30 \\
\hline \multirow[t]{4}{*}{ Marital status } & Single & 101 & 27.67 \\
\hline & Widowed/divorced & 8 & 2.19 \\
\hline & Cohabiting & 137 & 37.53 \\
\hline & Married & 119 & 32.60 \\
\hline
\end{tabular}

(66.85\%), and on urban or interstate $(75.07 \%)$, asphalt $(56.99 \%)$ roads in a poor state of repair (80.82\%). Motorcycles were the most common vehicle involved in the RTAs, accounting for $84.11 \%$ of victims' vehicles and $43.09 \%$ of the vehicles that hit them. The victim was the driver in $76.45 \%$ of cases $(n=327)$ (Table 2$)$. Most of the victims said they were using protective equipment when the accident occurred (73.39\%). According to the victims, the two leading causes of the RTA they were involved in were speeding (30.4\%) and dangerous driving (24.7\%).

\subsubsection{Immediate Post-Crash Interventions}

The police attended the scene of the accident immediately in 105 out of 365 cases (28.77\%), the fire service in 117 cases (32.05\%), and the ambulance service in 1 case $(0.27 \%)$. Together, the fire service and ambulance service attended the scene in 118 cases (32.33\%). According to victims' estimates, the median time taken for the emergency services to arrive on scene after the accident was 20 (10 - 30) minutes $(n=99)$. The police recorded the accident in less than a quarter of cases (79 cases, $22.07 \%)$. In most cases, the victim was transported to the health 
Table 2. Characteristics of the conflict and the vehicles involved, July 2018.

\begin{tabular}{|c|c|c|c|}
\hline Variables & & Number & $\%$ \\
\hline \multirow[t]{7}{*}{$\begin{array}{l}\text { Type of vehicle used by the } \\
\text { victim }(n=365)\end{array}$} & None (pedestrian) & 38 & 10.41 \\
\hline & Private motorcycle & 269 & 73.70 \\
\hline & Motorcycle taxi & 38 & 10.41 \\
\hline & Private car & 14 & 3.84 \\
\hline & Public transport car & 4 & 1.1 \\
\hline & Bus/minibus & 1 & 0.27 \\
\hline & Tricycle & 1 & 0.27 \\
\hline Victim's position $(\mathrm{n}=327)$ & Driver & 250 & 76.45 \\
\hline $\begin{array}{c}\text { Use of protective equipment } \\
\text { by the victim }(\mathrm{n}=327)\end{array}$ & Yes & 240 & 73.39 \\
\hline \multirow[t]{6}{*}{$\begin{array}{c}\text { Type of vehicle that hit the } \\
\text { victim }(\mathrm{n}=362)\end{array}$} & Pedestrian & 19 & 5.25 \\
\hline & Motorcycle & 156 & 43.09 \\
\hline & Car & 109 & 30.11 \\
\hline & Tricycle & 3 & 0.83 \\
\hline & None (victim fell without being hit) & 56 & 15.47 \\
\hline & Other & 19 & 5.25 \\
\hline
\end{tabular}

care facility by local residents, relatives or other road users (231 cases, 63.29\%), most commonly by motorcycle (168 cases, $46.15 \%$ ).

\subsubsection{Primary Care Seeking}

Most of the victims questioned said they had sought primary care from a health care facility -40 subjects (10.99\%) said they had visited a health centre, 297 subjects $(81.59 \%)$ sought care at a district or regional hospital, and 26 subjects sought care directly at the national referral hospital (CNHU). None of the subjects said they had sought care from a traditional masseur or prayer centre. The median time between arriving at the health care facility and being seen was 15 ( 5 - 30) minutes $(n=261)$. The lower limbs $(67.95 \%)$ and the head $(32.33 \%)$ were the most common injury sites. In addition, 185 subjects (50.68\%) had a single injury, $102(27.95 \%)$ had two injuries, and $78(21.37 \%)$ had three or more injuries.

\subsection{Disability and Associated Factors}

\subsubsection{Prevalence of Disability}

In total, 35 people were disabled, meaning they had a lot of difficulty performing the tasks in the six areas covered by the questionnaire, or could not perform them at all-a prevalence rate of 9.59\% (CI 95\%: 6.86\% - 13.20\%). Most of these people (32, or $91.43 \%$ ) had impairments in only one area. Mobility impairments were the most frequent type of difficulty $(80 \%)$. Commonly reported impair- 
ments included everyday mobility (25.7\%), and especially mobility and activities that take place outside the home, such as going up or down steps (28.6\%), leaving the home (34.3\%), and going shopping (25.7\%).

\subsubsection{Univariate Analysis}

There was a significant variation in the proportion of subjects reporting disability by age, with a higher percentage among people aged over 45 years $(p=$ 0.002). Moreover, a greater proportion of people in professional occupations reported disability (11.49\%) when compared with other occupational groups $(2.8 \%)(p=0.0077)$. No link was established between disability among RTA victims and gender, education, marital status or socio-economic well-being (Table 3).

From a statistical point of view, the environmental characteristics of the accident, the characteristics of the conflict, the user, and the types of vehicle involved had no impact on the likelihood of disability among RTA victims. The median time taken for the emergency services to arrive on the scene after the accident was higher among those victims who had developed a disability (30 (15 40) minutes) than among those who had not (17.5 (12.5 - 35) minutes), but the difference was not statistically significant $(p=0.397)$. The proportion of RTA victims having developed a disability differed according to whether or not the emergency services (fire service/ambulance service) attended the scene (0.0002),

Table 3. Socio-demographic traits and post-RTA disability, univariate analysis, July 2018.

\begin{tabular}{|c|c|c|c|c|c|}
\hline Variable & & No. & Disability (\%) & OR (CI 95\%) & $p$-value \\
\hline \multirow[t]{2}{*}{ Gender } & Female & 79 & 6.33 & 1 & 0.266 \\
\hline & Male & 286 & 10.49 & $1.73(0.65-4.63)$ & \\
\hline \multirow[t]{4}{*}{ Age } & $25-44$ & 219 & 6.85 & 1 & 0.031 \\
\hline & Under 25 & 45 & 6.67 & $0.97(0.29-3.31)$ & \\
\hline & $44-59$ & 73 & 17.81 & $2.95(1.38-6.30)$ & \\
\hline & 60 and above & 28 & 14.29 & $2.26(0.73-7.00)$ & \\
\hline \multirow[t]{2}{*}{ Marital status } & Single & 109 & 6.42 & 1 & 0.180 \\
\hline & Cohabiting & 256 & 10.94 & $1.79(0.76-4.23)$ & \\
\hline \multirow[t]{2}{*}{ Education } & Secondary school or higher & 247 & 8.10 & 1 & 0.161 \\
\hline & Primary school or lower & 118 & 12.71 & $1.65(0.81-3.36)$ & \\
\hline \multirow[t]{2}{*}{$\begin{array}{l}\text { Occupational } \\
\text { group }\end{array}$} & Not self-employed & 107 & 2.80 & 1 & 0.0077 \\
\hline & Self-employed & 235 & 11.49 & $4.5(1.33-15.18)$ & \\
\hline \multirow{3}{*}{$\begin{array}{l}\text { Socio-economic } \\
\text { well-being }\end{array}$} & Poor & 121 & 9.09 & 1 & 0.07 \\
\hline & Average & 120 & 5.83 & $0.62(0.23-1.66)$ & \\
\hline & Rich & 120 & 14.17 & $1.65(0.74-3.70)$ & \\
\hline
\end{tabular}

aSocio-economic well-being level has been categorised as tertiles, the lowest being "Poor" and the highest being "Rich". 
who transported the victim to the health care facility $(p=0.0001)$, and what mode of transport was used to transport the victim $(p=0.000)$. A greater proportion of victims developed a disability when the emergency services attended the scene of the accident, and when they were transported to the health care facility by the fire service or the police. Similarly, a smaller proportion of victims developed a disability when they were transported by motorcycle (Table 4).

There was no correlation between the likelihood of developing a disability, and the type of health care facility providing primary care or the distance between the scene of the accident and the health care facility. The median time between arriving at the health care facility and being treated was higher among those victims who had developed a disability (30 (10 - 45) minutes) than among those who had not (15 (5 - 32.5) minutes), but the difference was not statistically significant $(p=0.315)$. A link was established between the likelihood of developing a disability and the location of the injuries, in the sense that victims with head or neck injuries (OR: 2.77 CI 95\%: $1.37-5.61 ; p=0.0035$ ) and with lower limb injuries (OR: 2.45 CI 95\%: $1.01-6.08$; $p=0.0468$ ) were at the greatest risk of developing a disability. Moreover, although the proportion of victims who had developed a disability was higher as the number of injuries increased ( $p=$ 0.2578 ), no correlation could be established (Table 5). The results of the logistic regression were not shown due to collinearity between variables.

\section{Discussion}

\subsection{Characteristics of the RTA Victim Sample}

The RTA victim sample for this study was similar in many ways to other samples in the literature review. Most of the victims were male, as was the case in other contexts-between 71.7\% and 77\% in Ethiopia in 2015 [16] [17], 82\% in Yemen [18], and $69.8 \%$ in Kenya in 2013 [19]. Similarly, the findings of this study confirm what has been reported in various articles touching on this subject [17] [19]

Table 4. Immediate post-crash interventions and post-RTA disability, univariate analysis, July 2018.

\begin{tabular}{|c|c|c|c|c|c|}
\hline Variable & & No. & Disability (\%) & OR (CI 95\%) & $p$-value \\
\hline \multirow[t]{2}{*}{$\begin{array}{l}\text { Emergency services } \\
\text { attended the scene }\end{array}$} & Yes & 118 & 17.80 & 1 & 0.0002 \\
\hline & No & 247 & 5.67 & $0.28(0.14-0.57)$ & \\
\hline \multirow[t]{3}{*}{$\begin{array}{l}\text { Mode of transport used to } \\
\text { transport the victim }\end{array}$} & Fire service vehicle & 116 & 18.10 & 1 & 0.0001 \\
\hline & Normal car & 64 & 3.13 & $0.15(0.03-0.64)$ & \\
\hline & Motorcycle & 168 & 2.98 & $0.14(0.05-0.38)$ & \\
\hline \multirow[t]{2}{*}{$\begin{array}{c}\text { Person/people } \\
\text { transporting the victim }\end{array}$} & Fire service/police & 117 & 17.95 & 1 & \\
\hline & $\begin{array}{l}\text { Member of the } \\
\text { public/other user }\end{array}$ & 244 & 5.74 & $0.28(0.14-0.57)$ & 0.000 \\
\hline
\end{tabular}


Table 5. Location and number of injuries and post-RTA disability, univariate analysis, July 2018.

\begin{tabular}{cccccc}
\hline Variable & & No. & Disability (\%) & OR (CI 95\%) & $p$-value \\
\hline Head and neck & No & 247 & 6.48 & 1 & 0.0035 \\
Torso & Yes & 118 & 16.10 & $2.77(1.37-5.61)$ & \\
& No & 294 & 9.86 & 1 & 0.71 \\
Upper limbs & Yes & 71 & 8.45 & $0.84(0.34-2.12)$ & \\
No & 216 & 11.11 & 1 & 0.243 \\
Lower limbs & Yes & 143 & 7.69 & $0.28(0.14-0.57)$ & \\
& No & 117 & 5.13 & 1 & 0.0468 \\
Number of injuries & Yes & 248 & 11.69 & $2.45(1.01-6.08)$ & \\
& One & 185 & 7.57 & 1 & 0.2578 \\
& Two & 102 & 9.80 & $1.33(0.57-3.11)$ & \\
& Three or more & 78 & 14.10 & $2.01(0.87-4.64)$ & \\
\hline
\end{tabular}

[20] [21] - that young, working-age people (average age: 30 years) are more likely to be affected than other age groups. As regards occupation, Seid et al. (2015) found that manual workers (41.3\%) and students (12\%) were the two biggest groups in their sample. The fact that the findings of this study differ can be attributed to differences in the distribution of occupations among the general population from one country to the next [17]. In terms of the circumstances of the accident, the high proportion of motorcyclists is consistent with the findings of other studies in low- and middle-income countries: 68.2\% in Brazil (2015) [21], 55\% in Yemen (2015) [18], and 61.7\% in Ethiopia (2014) [16]. A high proportion of victims (73.4\%) reported having used protective equipment (helmet, seat belt) in our study. This figure is higher than what is normally reported in the literature: between $35.12 \%$ and $37.42 \%$ after intervention in Kenya [22], 5.7\% among motorcyclists in Cameroon (2012) [23], and 29\% in China (2015) [24]. Studies have showed a notable reduction in post-RTA morbidity and mortality among motorcyclists who wear a helmet [25], but there are differences in the law, and how it is applied, from one country to the next. Benin introduced a law on this subject in 2012, and its application has been supported by an effective awareness system and a subsequent enforcement campaign, especially in the country's big cities (Cotonou and Calavi in particular). As a consequence, more motorcyclists now wear a helmet, which probably explains the high percentage recorded in this study. However, the figure could also be attributed to bias, with respondents giving the answer expected of them because it they believed it was socially desirable to do so. Speeding is a major RTA risk factor. Speeding is recognised globally as a risk factor for causing RTAs, increasing the likelihood of serious injury in non-fatal RTAs, and increasing the likelihood that an RTA will be fatal [1] [26] [27]. In our study, 3 out of 10 victims said that speeding was the primary cause of the RTA-lower than the 66\% figure reported in China in an 
analysis covering 2007-2013 [28]. In Yemen, meanwhile, poor driving skills is the number-one reported cause of RTAs ( $85 \%$ of cases) [18]. These differences can be attributed both to contextual factors and to differences in methodology (and to how the modalities of the variable are defined in particular). Our findings support what has been widely reported in the literature-that the majority of injuries are sustained to the head and lower limbs [17] [19].

\subsection{Disability and Associated Factors}

In their study in Brazil, Rocha et al. reported "disability" among 50\% of RTA victims [21]. This figure is higher than the $10 \%$ reported in this study, and by Palmera-Suarez et al., who indicated a figure of 2.1 per 1000 population in Spain [9]. These differences can, however, be attributed not just to contextual elements but also to different methodologies. In the Brazilian and Spanish studies, disability was evaluated using WHO's International Classification of Functioning, Disability and Health (ICF). In our study, however, we used the United Nations' (UN) Washington Group on Disability Statistics questionnaire. In addition, the Spanish study was based on a national disability survey (community survey), whereas our study, and the one in Brazil, used hospital data. Studies documenting post-RTA disability are few and far between, and comparing them is still difficult because the definitions of disability and subject selection methods vary from one to the next. The systematic review of the issue, conducted in 2004, confirms this state of affairs, revealing a broad range of estimated prevalence rates (between $2 \%$ and $87 \%$ ) across different studies and a tendency among authors to stress the methodological challenges that researching this phenomenon poses [29].

On the link between socio-demographic traits and disability, comparing the findings of our study with those typically seen in the literature presents a mixed picture. Our study found that age was a risk factor, with a greater likelihood of disability among subjects aged over 45 years - similar to the findings of the 2008 Spanish study. This correlation can be attributed to the fact that younger people's bodies are better equipped to recover from injury. However, our study found no correlation between disability and other socio-economic traits such as gender, education or socio-economic well-being. These findings are at odds with Palmera-Suarez et al., who revealed that likelihood of disability is contingent on both education and socio-economic well-being [9]. Our study also found a relationship between post-RTA disability and occupational group, revealing that people in self-employed occupations (freelance professionals, shopkeepers/traders, and crafts/tradespeople) are more likely to develop a disability after an RTA than members of other groups (pupils/students, housekeepers, unemployed people and civil servants). This difference could be attributed to differing perceptions of impairment because of the type of work that members of each group perform. In other words, people in self-employed occupations consider their impairments to be more serious because they place greater restrictions on their mobility.

Our findings indicate that the environmental characteristics of the accident, 
the characteristics of the conflict, the user, and the types of vehicle involved have no impact on the likelihood of disability among RTA victims. Looking at this lack of statistical correlation from a different angle, it could suggest that all RTA victims are at equal risk of disability-pedestrians, motorcyclists and car drivers have the same level of risk, as do passengers and drivers, and as do people involved in accidents caused by speeding or poor road conditions.

Quick, effective post-RTA interventions are part of tertiary prevention efforts and are designed to limit the impact of RTAs on victims' health. Our study showed that victims were more likely to develop a disability if the emergency services attended the scene of the accident than if they did not. Similarly, victims transported by motorcycle were less likely to develop a disability than those transported in a fire service vehicle, while the likelihood of developing a disability was lower among victims transported by a member of the public. Although these findings appear to run counter to common sense, they could be attributed to the fact that people are largely unaware of the emergency services available to them when an accident happens, and of the financial implications of using these services. Consequently, victims do not systematically call the emergency services because they do not know how to contact them or because they are fearful of the costs, even though the services are free of charge. In addition, people only tend to contact the police or the fire service when they have no other option-i.e. in the case of severe injuries or when the victim cannot be transported by motorcycle or by a member of the public. This explains why only the most serious injuries (i.e. those that could leave the victim disabled) are treated by the emergency services, and why our study revealed these findings. Considering the severity of injuries would help to clarify the relationship and would make an interesting avenue of research in future studies. Our study indicated that it took longer for the emergency services to arrive on the scene, and for the victim to be seen at the health care facility, among victims who developed a disability than those who did not. Although we were unable to establish a statistically significant difference, it would be a worthwhile exercise to explore these factors in future studies. The fact that we were unable to establish a difference could well be linked to the shortcomings of this study. Because of its retrospective nature, it introduced inherent bias in the variables and recorded a high non-response rate since subjects were required to remember precise information such as timings. The location of injuries influences the severity of an RTA, and several studies have pointed to the fact that RTAs have more serious consequences when the victim suffers head injuries [19] [30]. Our study confirmed these findings, showing that victims with head injuries were three times as likely to develop a disability as those without head injuries. Similarly, victims with lower limb injuries were twice as likely to develop a disability as those without lower limb injuries. Mobility impairment was the most common form of disability among RTA victims, affecting both the body as a whole (resulting from head of neck injuries) and peripheral parts of the body (resulting from limb injuries). Body-wide mobility impairment caused by a head or neck injury occurred most often from 
damage to the central nervous system and was most likely to cause persistent damage and, ultimately, disability. These findings underscore why it is so important for motorcyclists to wear helmets to prevent head injury [1] [19].

\subsection{Limitations of the Study}

The aim of this study was to estimate the prevalence of disability among RTA victims and to identify the associated factors. The findings suggest that we achieved our objectives and that the results can be extrapolated to all RTA victims treated in Cotonou and Calavi hospitals. The study is limited in its scope for two reasons. First, as a transverse study, it was not possible to guarantee the historical nature of the explanatory factors. And second, the fact that it was a retrospective study introduced the possibility of memory-related bias. We decided to limit the study to victims treated within the previous 18 months to reduce the prospect of memory-related bias. Moreover, because our study focused on disability, the decision to select primary targets from victims treated in hospital could have introduced selection bias in certain contexts. However, given the severity of RTA-induced injuries, we can confidently posit that selection bias was not a major issue because most victims sought treatment at a health care facility. Lastly, because the study was designed around a community survey, it did not take account of hospital statistics such as clinical and treatment quality data. Consequently, we did not include in our analysis all those factors that could have influenced the likelihood of developing a disability. For that reason, supplementing our findings with other, forward-looking and hospital-based studies would be a worthwhile exercise.

\section{Conclusion}

There is a relationship between the likelihood of a road traffic accident (RTA) victim developing a disability, and the victim's age and the location of the injuries. Public policy-makers should therefore focus on stepping up interventions to get more people using protective equipment, especially helmets and seat belts, and on better communicating with the general public about the link between RTAs and disability, and about the importance of using post-crash response services. There is scope to strengthen the findings of this study. We did not consider temporal aspects in our definition of disability. It would be useful to include this notion in the definition of post-RTA disability. For that reason, it would be worth building on the findings of our study with a forward-looking cohort study that monitors RTA victims regularly over a period of time to evaluate impairment, incapacity, and the emergence and consolidation of disability. Such a study could also produce more detailed findings by taking account of hospital data.

\section{Availability of Data and Materials}

Data collection tools, dataset used and analyzed during the current study are 
available from the first author on reasonable request.

\section{Acknowledgements}

We would like to thank the Académie de la Recherche et d' Enseignement Supérieur (ARES) for financially supporting this study. We are also sincerely grateful to all the victims who agreed to contribute to this research.

\section{Conflicts of Interest}

The authors declare no conflicts of interest regarding the publication of this paper.

\section{References}

[1] World Health Organization (2015) Global Status Report on Road Safety. WHO, Geneva, 340 p.

[2] Alemany, R., Ayuso, M. and Guillen, M. (2013) Impact of Road Traffic Injuries on Disability Rates and Long-Term Care Costs in Spain. Accident, Analysis and Prevention, 60, 95-102. https://doi.org/10.1016/j.aap.2013.08.016

[3] Sanchez-Vallejo, P.G., Perez-Nunez, R. and Heredia-Pi, I. (2015) [Economic Cost of Permanent Disability Caused by Road Traffic Injuries in Mexico in 2012]. Cadernos de saude publica, 31, 755-766. https://doi.org/10.1590/0102-311X00020314

[4] World Health Organization (2010) Plan mondial pour la Décennie d'Action pour la Sécurité Routière 2011-2020. WHO, Geneva, 24 p.

[5] Beck, B., Cameron, P.A., Fitzgerald, M.C., Judson, R.T., Teague, W., Lyons, R.A., et al. (2017) Road Safety: Serious Injuries Remain a Major Unsolved Problem. The Medical Journal of Australia, 207, 244-249. https://doi.org/10.5694/mja17.00015

[6] Ernstberger, A., Joeris, A., Daigl, M., Kiss, M., Angerpointner, K., Nerlich, M., et al. (2015) Decrease of Morbidity in Road Traffic Accidents in a High Income Country-An Analysis of 24,405 Accidents in a 21 Year Period. Injury, 46, S135-S143. https://doi.org/10.1016/S0020-1383(15)30033-4

[7] Adeloye, D., Thompson, J.Y., Akanbi, M.A., Azuh, D., Samuel, V., Omoregbe, N., et al. (2016) The Burden of Road Traffic Crashes, Injuries and Deaths in Africa: A Systematic Review and Meta-Analysis. Bulletin of the World Health Organization, 94, 510-521. https://doi.org/10.2471/BLT.15.163121

[8] Organisation Mondiale de la Santé, Banque Mondiale (2012) Rapport mondial sur le handicap 2011. WHO, Malte, 384 p.

[9] Palmera-Suarez, R., Lopez-Cuadrado, T., Almazan-Isla, J., Fernandez-Cuenca, R., Alcalde-Cabero, E. and Galan, I. (2015) Disability Related to Road Traffic Crashes among Adults in Spain. Gaceta Sanitaria, 29, 43-48. https://doi.org/10.1016/j.gaceta.2015.01.009

[10] Centre National de Securité Routière (2018) Annuaire des statistiques de accidents de la voie publique au Bénin 2016. Centre National de Securité Routière, Cotonou.

[11] Institut National de la Statistique et de l'Analyse Economique (2013) Synthèse des prinicipaux résultats du RGPH-4: Plaquette Atlantique. Institut National de la Statistique et de l'Analyse Economique, Cotonou.

[12] Institut National de la Statistique et de l'Analyse Economique (2013) Synthèse des prinicipaux résultats du RGPH-4: Plaquette Littoral. Institut National de la Statistique et de l'Analyse Economique, Cotonou. 
[13] Madans, J.H., Loeb, M.E. and Altman, B.M. (2011) Measuring Disability and Monitoring the un Convention on the Rights of Persons with Disabilities: The Work of the Washington Group on Disability Statistics. BMC Public Health, 11, S4. https://doi.org/10.1186/1471-2458-11-S4-S4

[14] Lollar, D.J. and Horner-Johnson, W. (2016) Public Health Dimensions of Disability. International Encyclopedia of Public Health. 190-199.

[15] Vyas, S. and Kumaranayake, L. (2006) Constructing Socio-Economic Status Indices: How to Use Principal Components Analysis. Health Policy and Planning, 21, 459-468. https://doi.org/10.1093/heapol/czl029

[16] Hailemichael, F., Suleiman, M. and Pauolos, W. (2015) Magnitude and Outcomes of Road Traffic Accidents at Hospitals in Wolaita Zone, SNNPR, Ethiopia. BMC Research Notes, 8, 135. https://doi.org/10.1186/s13104-015-1094-Z

[17] Seid, M., Azazh, A., Enquselassie, F. and Yisma, E. (2015) Injury Characteristics and Outcome of Road Traffic Accident among Victims at Adult Emergency Department of Tikur Anbessa Specialized Hospital, Addis Ababa, Ethiopia: A Prospective Hospital Based Study. BMC Emergency Medicine, 15, 10.

https://doi.org/10.1186/s12873-015-0035-4

[18] Alfalahi, E., Assabri, A. and Khader, Y. (2018) Pattern of Road Traffic Injuries in Yemen: A Hospital-Based Study. The Pan African Medical Journal, 29, 145. https://doi.org/10.11604/pamj.2018.29.145.12974

[19] Sisimwo, P.K., Mwaniki, P.K. and Bii, C. (2014) Crash Characteristics and Injury Patterns among Commercial Motorcycle Users Attending Kitale Level IV District Hospital, Kenya. The Pan African Medical Journal, 19, 296.

https://doi.org/10.11604/pamj.2014.19.296.4885

[20] Mokdad, A.H., Forouzanfar, M.H., Daoud, F., Mokdad, A.A., El Bcheraoui, C., Moradi-Lakeh, M., et al. (2016) Global Burden of Diseases, Injuries, and Risk Factors for Young People's Health during 1990-2013: A Systematic Analysis for the Global Burden of Disease Study 2013. The Lancet, 387, 2383-2401. https://doi.org/10.1016/S0140-6736(16)00648-6

[21] Rocha, G.D., Mello Jorge, M.H. and Grembek, O. (2017) After-Effects and Disabilities in Traffic Crash Victims in Northern Brazil. Traffic Injury Prevention, 18, 412-419. https://doi.org/10.1080/15389588.2016.1213391

[22] Bachani, A.M., Hung, Y.W., Mogere, S., Akunga, D., Nyamari, J. and Hyder, A.A. (2017) Helmet Wearing in Kenya: Prevalence, Knowledge, Attitude, Practice and Implications. Public Health, 144, S23-S31. https://doi.org/10.1016/j.puhe.2016.12.005

[23] Chichom-Mefire, A., Atashili, J., Tsiagadigui, J.G., Fon-Awah, C. and Ngowe-Ngowe, M. (2015) A Prospective Pilot Cohort Analysis of Crash Characteristics and Pattern of Injuries in Riders and Pillion Passengers Involved in Motorcycle Crashes in an Urban Area in Cameroon: Lessons for Prevention. BMC Public Health, 15, 915. https://doi.org/10.1186/s12889-015-2290-4

[24] Fong, M.C., Measelle, J.R., Dwyer, J.L., Taylor, Y.K., Mobasser, A., Strong, T.M., et al. (2015) Rates of Motorcycle Helmet Use and Reasons for Non-Use among Adults and Children in Luang Prabang, Lao People's Democratic Republic. BMC Public Health, 15, 970. https://doi.org/10.1186/s12889-015-2304-2

[25] Liu, B.C., Ivers, R., Norton, R., Boufous, S., Blows, S. and Lo, S.K. (2008) Helmets for Preventing Injury in Motorcycle Riders. The Cochrane Database of Systematic Reviews, Cd004333.

[26] Potoglou, D., Carlucci, F., Cira, A. and Restaino, M. (2018) Factors Associated with 
Urban Non-Fatal Road-Accident Severity. International Journal of Injury Control and Safety Promotion, 25, 303-310. https://doi.org/10.1080/17457300.2018.1431945

[27] Batool, I., Hussain, G., Kanwal, N. and Abid, M. (2018) Identifying the Factors behind Fatal and Non-Fatal Road Crashes: A Case Study of Lahore, Pakistan. International Journal of Injury Control and Safety Promotion. https://doi.org/10.1080/17457300.2018.1456466

[28] Chen, Y., Li, Y., King, M., Shi, Q., Wang, C. and Li, P. (2016) Identification Methods of Key Contributing Factors in Crashes with High Numbers of Fatalities and Injuries in China. Traffic Injury Prevention, 17, 878-883. https://doi.org/10.1080/15389588.2016.1174774

[29] Ameratunga, S.N., Norton, R.N., Bennett, D.A. and Jackson, R.T. (2004) Risk of Disability Due to Car Crashes: A Review of the Literature and Methodological Issues. Injury, 35, 1116-1127. https://doi.org/10.1016/j.injury.2003.12.016

[30] Siddiqui, S.M., Sagar, S., Misra, M.C., Gupta, A., Crandall, M. and Swaroop, M. (2016) Patterns of Injury among Motorized Two-Wheeler Pillion Riders in New Delhi, India. The Journal of Surgical Research, 205, 142-146.

https://doi.org/10.1016/j.jss.2016.06.033 